\title{
Digitalization and the Challenges for the Accounting Profession
}

\author{
Danimir Gulin \\ Faculty of Economics and Business, University of Zagreb, Croatia \\ Mirjana Hladika \\ Faculty of Economics and Business, University of Zagreb, Croatia \\ Ivana Valenta \\ Faculty of Economics and Business, University of Zagreb, Croatia
}

\section{Abstract}

Accounting profession is traditional profession and accounting rules and principles have been established and are the same for many years. However, globalization of business, stronger regulations and numerous technological solutions and innovations are not bypassing the accounting profession either. Challenges for the accounting profession are reflected in the need for rapid adaptation and transformation of business practice and business processes without abandoning away from basic accounting rules and principles. The aim of this paper is to analyze and systematize the key challenges that digitalization brings for the accounting profession. Research is based on the review of relevant and available professional and academic literature. The results are showing that accounting profession is faced with numerous challenges in the era of digitalization. Key challenges could be systematized in following: the use of big data in accounting and reporting, cloud computing and continuous accounting, artificial intelligence and blockchain technology. The conclusion of this research is that changes in technology and digitalization will have a significant impact on the accounting profession in the coming period. Changes are moving toward reporting on a daily basis, difference on the way of preparing business and strategic plans, implementation of digital wallet and on-line accounting as well as outsourcing of accounting in distant countries. Education system is going to change in circumstances of growing digitalization of business. Also, users of accounting information in digital era are changing; they want accounting information right away when a business event occurs, not with time lag. Those changes will influence on the way accountants carry out their job, it will be necessary the knowledge of new skills especially in engineering, and, finally, that will lead to new types of the accounting professionals.

Keywords: digitalization, big data and reporting, cloud computing, artificial intelligence, accounting profession, accountants' skills

JEL classification: M40, M41, M49

\section{Introduction}

Digital technology has an impact on the strategic and competitive aims of the company, but also it affects on the business models, competitive advantages as well as on company's approach to the market. Also, there is a significant influence of digital technology on the accounting information and management control systems (Mancini et al., 2017). Accounting rules and principles have been established for many years and they do not change over time. On the other hand, 
accounting industry is evolving and it changes. As a consequence of development of technology, the coverage of accountants' tasks and activities is transforming and client expectations are changing. Development of technology and digitalization allow updates and changes of accounting profession. Development of modern computer systems leads to reducing the workload of accountants; repetitive actions that existed in environment of traditional methods are made easy and quickly.

Technological developments, globalization and increasing competition force professions to change constantly. The accountancy profession is at the forefront of professions that is and will be most affected by technological developments and globalization. It is evident that, with technological development, many digital systems that did not exist ten years ago are now actively used in the accountancy profession (Tekbas, 2018). According to results of the research conducted by Frey et al. (2017) 702 job titles are at risk of automation, and the accounting profession in on the top of this list with high probability of being automated and digitalized in the near future.

Goal of this paper is to systematize and analyze key changes in the accounting profession that will be affected by the digitalization. Research is based on the review of available relevant professional and academic literature.

Paper is structured into five parts. First part of the paper is introduction, while second part consists of the literature review. Methodology that is used in the paper is presented in third part. The influence of the digitalization on accountants' activities and tasks and main digital solutions for accountants are presented in fourth part of the paper. Main conclusions and limitations of the research as well as directions for future research are presented in the last part of the paper.

\section{Literature review}

In order to assess the possibility for automation of accounting tasks and processes, it is needed to distinguish routine tasks that can easily be automated and nonroutine tasks that are difficult to be conducted by machines or software. Oschinski et al. (2017) highlighted that jobs and tasks that require critical thinking, high-level creativity and training as well as human contact will not be automated soon. However, routine tasks which do not require high level of education and training and that require a little human communication can be easily automated (Kim et al., 2017).

According to Arntz et al. (2017) many accounting tasks already are automated in many companies (especially in large companies). Those tasks are invoicing, payroll and bookkeeping and they are automated because they consist of routine, repeated, stable and structured actions. Moudud-UI-Huq (2014) highlighted that digitalization and automation is helpful for the auditors during the following processes: audit planning, analytical review procedures, materiality assessment, internal control evaluation, risk assessment and going-concern decisions.

There are a few researches that analyse how many companies today use digital solutions, and what they expect to use in next few years. Those researches are mainly initiated and implemented by biggest audit firms.

KPMG conducted a study on Digitalisation in accounting, and main digital solutions that are already implemented in companies in Germany or will be implemented in the near future, and they are: paperless accounting, interfaces to internal or external systems, management of data quality, process automation, uniformity of systems, integrated consolidation system, real time reporting, creation 
of transparency, big data analyses, tools for visualisation and cloud computing (KPMG, 2017).

PWC made a survey on a sample of 76 large and medium sized companies based in Germany about the current status and further digital development. The most popular areas for artificial intelligence for the companies surveyed are automatic reading of invoices and documents for accounting (39\% of responses) and automated payment transfers (29\%). Third place on the list of priorities is shared by monitoring data and consistency checking of documents, with $10 \%$ of responses each (PWC, 2018).

In survey conducted by PWC, one of the questions referred to plans which companies have toward using new technologies. Answers showed that $22 \%$ of interviewed companies will start using document recognition, $20 \%$ will in the near future start sharing data directly with customers and suppliers, $19 \%$ of companies will use payment transfers and $14 \%$ of companies find replacement of Excel worksheets.

In 2017 KPMG conducted a research about which of the following statements on digitalization in accounting will apply to their company in the next year. The results are similar to results of the survey conducted by PWC. Most of the companies that participated in the research will implement paperless accounting, uniformity of systems and interfaces to external systems. Most of them will also apply management of data quality and integrated consolidation system and also a big data analyses (KPMG, 2017).

As a result of these researches it can be concluded that companies are preparing for the implementation and changes in business as result of digitalization. Implementation of a new software support solutions is a very long and expensive process, especially if it is about internal solution development. For that reason, a lot of companies that provide services and develop new solutions for accounting system see here a big chance. Companies that have already implemented new solutions or are in the phase of implementation are primarily large companies due to the fact that in smaller companies' implementation of costly solutions is not costeffective.

\section{Methodology}

In order to achieve the research goals, available relevant professional and academic literature were studied and analyzed. Academic literature was obtained from searching the following databases - Proquest, EBSCO Host, and Web of Science. The following search subject was used - digitalization in accounting, changes and trends in accounting profession, cloud computing, artificial intelligence, big data and blockchain technology. We selected most relevant articles (for the topic of this paper) that were written in English and for which the full paper was available. Professional papers were gathered through searching the web pages of biggest audit firms and professional bodies for accountants and auditors. Research included subjects in the area of digitalization and its effect on the accounting profession. Selected academic and professional papers were analyzed by using scientific-research methods as it is induction and deduction method, method of analysis and synthesis, generalization method and abstraction method. 


\section{Results}

\section{Digitalization and accounting profession}

There are different reasons why accountants should accept and apply modern digital solutions. Factors that can have a significant impact and be a motivation for technological change according to study conducted by Wilson et al. (1992) among the UK accounting profession are as follows: need to meet prescribed deadline for accounting tasks and the importance to provide better and timely information for different users. Furthermore, by using technology the quality and relevance of the accounting information will be improved (Al-Htaybat et al., 2017), the period needed for preparation will be shortened and information will be available in real time without delay.

With accounting processes becoming automated and less time-intensive, accountants are becoming more connected to their clients and are increasing their advisory services when it comes to daily business operations. In their study, Herbert et al. (2016) investigated that digitalization and automation are used in order to eliminate or minimize routine and repetitive tasks, so it will enable employees (accountants) to focus on more creative, non-routine and nonstructured tasks that required more thinking and additional skills. This change in approach will have an impact on the future activities of experienced accountants. Because most services are now cloud-based and financial data is available preferable quickly, companies (clients) are willing to change accounting firms faster than in the past if they are unsatisfied with the services they receive.

Despite digitalization and automation have many advantages for successful conducting a business and perform accountant's tasks, it has to be pointed out that automation and artificial intelligence could not perform accountant's most valuable functions which are interpreting and analysing financial information (Zarowin, 1994). According to results conducted by Kokina et al. (2017) about the current capabilities of cognitive technologies and the influence of these technologies on auditors and audit process, the senior accountants indicated that the need for human accountants would not go away anytime soon.

A positive prediction of automatization is that machines and robotic automation will enhance the value of services, not diminish it. Basic services can and will be delivered even more efficiently, allowing accountants to have more time to discuss their client's current situation and future needs.

Accountants and financial advisors will use the same tools to move from data entry, recordkeeping and simple analysis to strategic business consultancy. Primary analytics programs such as Excel will probably be replaced. Financial controllers and CFOs start using structured data, unstructured data, and predictive analytics to access large base of customer information, financial trends and industry information to make insightful forecasts.

Technological development and technologies like the cloud, artificial intelligence and blockchain will strengthen the role of accountants and the entire financial industry, because reducing manual data entry and improving the speed, quality and accuracy of data.

In the 21 st century, the accountancy profession needs a new model able to respond to technological changes and developments in the process of digitalization and e-transformation so that the accounting profession is more effective. Accounting Engineering is the redesign of the accountancy profession in light of technological developments, such as digitalization, artificial intelligence, and the Fourth Industrial Revolution (Tekbas, 2018). Accounting Engineering will 
enable accountants to use different digital systems to acquire the right knowledge and to manage and use technology in the learning-teaching process. An accounting engineer is a person who can adapt to technological developments and actively use technological products in professional practices, combine practical and theoretical knowledge with philosophy, mathematics, and technology (Tekbas, 2018).

Digitalization implies a different philosophy in the way in which companies are managing and conducting their business, processes and activities (Mancini et al., 2017). According to Mancini (2016), keywords that characterise the philosophy of digital technology are ubiquity, openness and sharing. Accordingly, data and information are freely available, and their flow is without restrictions among organisations and groups of people. Availability of comprehensive data about the business in real time in the era of digitalization will have a significant impact on the way companies prepare their strategic plans. Data that are available to managers are more accurate, various and present current trends, so companies' strategic plans are more appropriate to a modern business environment.

The existence of digital wallet as an electronic or online service has a significant impact on the customers' confidence on the online trade and the volume of electronic transactions. Payments for goods and services purchased online are secure for the personal information and for the actual transaction. Digital wallets are developed and designed in order to be accurate when transferring data to retail checkout forms.

\section{Main digital solutions for accountants}

Main digital solutions that have a big impact on accounting profession are:

\section{Artificial intelligence}

Smart technologies like Artificial intelligence and machine learning have been actively providing near-real-time information to businesses. Artificial intelligence and automation can significantly reduce the need for human labour, and it can be integrated into accounting and auditing processes. Artificial intelligence can be successfully applied for more structured, programmable and repetitive tasks where gathering human knowledge and expertise is not extremely difficult and demanding (Moudud-UI-Huq, 2014). Smart technologies are not developing to extinct human intelligence but to help accountants to become better strategic advisors by providing crucial business insights. Artificial intelligence and machine learning will give accountants better access to a range of near-real-time information from a greater number of sources. Although Artificial intelligence is still in the early stages of development, it was already being used by $18 \%$ of the companies surveyed at the end of 2017, particularly for smart document OCR (Optical Character Recognition) and automating payment transfers (PWC, 2018). Development of the software leads to understanding of invoices rather than simply matching order numbers and invoice amounts.

\section{Blockchain}

Blockchain allow businesses to access the same information in real-time from different sources. Majority of businesses are utilizing this delivery method to secure their sensitive accounting data and speed-up complex processes. Referring blockchain as a technology for cryptocurrency is not valid. Along with uninterrupted security and transparency, blockchain is capable enough to replace traditional ways of handling auditing, compliance and reconciliation tasks. Results 
of the survey conducted by PWC on a sample of German companies showed that $8 \%$ of the companies surveyed use blockchain technology. And those who are already using blockchain want to use it above all to ensure data integrity, process transactions and manage customer and supplier relations. It is also used for signing contracts (PWC, 2018).

\section{Continuous accounting}

Technology development provides new opportunities for providing information on a daily basis. Accounting is still based on a periodic review and analysis of financial information, but stakeholders, auditors and others expect comprehensive and real time reporting. Implementing and transitioning, from a periodic basis of accounting and reporting focused strictly on financial information to a more comprehensive view of accounting reporting will require a transition period and implementation steps. Implementing and transitioning to a more comprehensive accounting function will result in some displacement and disruption of current roles (Smith, 2018).

Big data

Big data and data analytics will affect accounting in many ways; for example by influencing how business is conducted and how financial statements are prepared and audited. Also, big data have a significant impact on the quality of decision making process, because the measurement of data has been enhanced, data are comprehensive and the information is better understood (Liu et al., 2014). Availability of comprehensive data through digital solutions increases the effectiveness and efficiency of accountants. Big data can reduce the time for reporting because modern technologies provide real time updates. With analytic skills and tools, professionals can effectively analyse data and get an insight into data that will change the way business decisions are made. Big data will have influence on financial and managerial accounting, but also on auditing. Big data describes extremely large datasets typically greater than a petabyte that have particular storage challenges and generally need to be analysed using computational methods.

Related to accounting and information systems, the most significant impact of the development of information technology is the impact on data management, or how companies manage data processing in order to get reliable information (Mancini et al., 2017).

In her article, Cockroft (2018) made review of articles of big data in academic research in accounting and finance. Results showed six under-researched areas of big data in accounting and finance. These areas are privacy and security, data visualisation and predictive analytics, data management and data quality. Increased research in these areas will lead to improvements in industry practices, and more opportunities for cross-disciplinary research.

In Table 1 are presented key effects that digitalization will have on the accounting profession and performing of accounting tasks. 
Table 1

Key Effects of Digitalization on the Accounting Profession and Performing of Accounting Tasks

\begin{tabular}{ll}
\hline Area & Effect \\
\hline Main digital solutions & Artificial intelligence \\
& Blockchain \\
& Cloud computing \\
& Big data \\
Performing accounting & Automatization of routine, repetitive and structured tasks \\
(e.g. invoicing, payroll) & Non-routine and non-structured tasks will require human \\
thinking and additional skills and knowledge (e.g. \\
interpreting and analysing financial information)
\end{tabular}

Source: Authors' work

In order to keep adding value for the company, accountants need to developed new skills and acquire new knowledge regarding the use of artificial intelligence and other digital solutions in modern business environment. There is highlighted the need of all employees (including accountants) for development of critical thinking and problem solving, high level of adaptability, flexibility and interpersonal interaction; it is required to learn continuously (David, 2015; Marcello et al., 2017). For successful career of future accountants are important many skills and those are motivation, good written and oral communication, capability of decision making, financial analysing and professional judgement (Parham et al., 2012). Change in education is crucial and the education system should change by focusing on critical and system thinking with the aim to develop creativity skills of students. Finally, accountants will have a significant proactive role in conducting and performing company's business, so it is required that they will collaborate with employees in other functions, especially with IT experts.

\section{Conclusion}

Digitalization and the development of information technologies represent a great opportunity for companies. Furthermore, digitalization brings a lot of changes for accounting profession. It will change the way accountants work and think. Despite many of accountants think that digitalization will take their jobs, and that robots will replace humans, results show that accountants will use digital solutions and automation for routine tasks rather than replace accountants. There are tasks and activities of accountants that require critical thinking and creativity, so it would be not so easy to automate those tasks and activities. Accordingly, digitalization will affect the development of accounting profession. Accountants should be ready for automation and that requires specific and new knowledge and skills of accountants. Routine, repetitive and structured tasks of accountants are or will be automated in near future. Wider network of information, knowledge based system and data mining are powerful tools for successfully running a business. New digital solutions as artificial intelligence, blockchain, big data, cloud computing and 
continuous accounting etc. will affect on reducing manual data entry and improving the speed, quality and accuracy of data. As a consequence of automation, the businesses can run very smoothly. Profession will transform from bookkeepers and accountants to advisors, consultants and accountants engineers. So, to the possible develop, accountants need to seize the opportunity of development of technology that facilitates and enhances their profession.

Digitalization of processes and implementation of new software(s) that enable knowledge-based management is very expensive, and it is available only for large companies.

The process of digitalization of accounting and financial reporting on the daily basis connected with the financial markets could have a significant impact on the investor's decisions, especially on small investors. The main reason for this is contained in a daily balance sheet that is available to financial statement users in the environment of digitalization of accounting and financial reporting.

Finally, despite of wide range of accountants' activities and tasks that can be automated, human intelligence will always exceed machine learning.

The practical implication of this paper can be summarized in the fact that accountants will shift their current activities to either advisory or consultancy. Furthermore, IT, analytical and tax knowledge and skills of accountants will have to be developed. Finally, those changes will require that universities change and modify their education programs in order to prepare accounting students for work in modern environment along automation and digitization.

Limitation of this study is related to the coverage of analyzed literature, because it is not comprehensive. Although, the use of digitalization and automation is global, there are still scarce professional and academic researches about the application of digitalization in accounting and its impact on the accounting profession (especially in certain countries).

Future research should be directed toward primary research through a survey as well as in-depth interviews in order to gain knowledge about the changes the role of accountants in environment of digitalization and automation and the use of artificial intelligence, and about the accounting tasks that are automated in companies with different size (micro, small, medium and large).

\section{References}

1. Al-Htaybat, K., von Alberti-Alhtaybat, L. (2017), "Big Data and corporate reporting: impacts and paradoxes", Accounting, Auditing and Accountability Journal, Vol. 30, No. 4, pp. 850-873.

2. Arntz, M., Gregory, T., Zierahn, U. (2017), "Revisiting the risk of automation", Economics Letters, Vol. 159, pp. 157-160.

3. Cockroft, S. (2018), "Big Data Opportunities for Accounting and Finance Practice and Research: Big Data in Accounting and Finance", available at: https://www.researchgate.net/publication/322938351_Big_Data_Opportunities_for Accounting_and_Finance_Practice_and_Research_Big_Data_in_Accounting_and Finance (11 April 2019).

4. David, H. (2015), "Why are there still so many jobs? The history and future of workplace automation", Journal of Economic Perspectives, Vol. 29, No. 3, pp. 3-30.

5. Frey, C. B., Osborne, M. A. (2017), "The future of employment: How susceptible are jobs to computerisation?", Technological Forecasting and Social Change, Vol. 114, pp. 254-280.

6. Herbert, I., Dhayalan, A., Scott, A. (2016), "The future of professional work: will you be replaced, or will you be sitting next to a robot?", Management Services Journal, 2016 (Summer), pp. 22-27. 
7. Kim, Y. J., Kim, K., Lee, S. (2017), "The rise of technological unemployment and its implications on the future macroeconomic landscape", Futures, Vol. 87, pp. 1-9.

8. Kokina, J., Davenport, T. H. (2017), "The Emergence of Artificial Intelligence: How Automation is Changing Auditing", Journal of Emerging Technologies in Accounting, Vol. 14, No. 1, pp. 115-122.

9. KPMG (2017), "Digitalisation in accounting", available at: https://hub.kpmg.de/digitalisierung-im-rechnungswesen2017 ? utm_campaign=Digitalisierung\%20im\%20Rechnungswesen\&utm_source=AEM \& hstc $=214917896.3 \mathrm{a} 0 \mathrm{~d} 5 \mathrm{dcb} 67 \mathrm{dcclc} 3314090953 \mathrm{e} 2 \mathrm{c} 528 \mathrm{~d} .1556354963109 .1556354$ $963109.1556467129734 .2 \& \quad$ hssc $=214917896.1 .1556467129734 \& \quad$ hsfp $=1828149151$ (18 April 2019).

10. Liu, Q., Vasarhelyi, M. A. (2014), "Big Questions in AlS Research: Measurement, Information Processing, Data Analysis, and Reporting", Journal of Information Systems, Vol. 28, No. 1, pp. 1-17.

11. Mancini, D. (2016), "Accounting information systems in an open society - Emerging Trends and Issues", Management Control, Vol. 1, pp. 5-16.

12. Mancini, D., Lamboglia, R., Castellano, N. G., Corsi, K. (2017), "Trends of Digital Innovation Applied to Accounting Information and Management Control Systems", in Corsi, K., Castellano, N. G., Lamboglia, R., Mancini, D. (Eds.), Reshaping Accounting and Management Control Systems - New Opportunities from Business Information Systems, Springer, Cham, Switzerland, , pp. 1-19.

13. Marcello, S., Ray, T., Carmichael, D., Peterson, J., Ramamoorti, S. (2017), "The Future of Auditing: A Roundtable Discussion", The CPA Journal, pp. 39-57.

14. Moudud-UI-Huq, S. (2014), "The Role of Artificial Intelligence in the Development of Accounting Systems: A Review", The UIP Journal of Accounting \& Audit Practices, Vol. 12, No. 2, pp. 7-19.

15. Oschinski, M., Wyonch, R. (2017), "Future stock? The impact of automation on Canada's labour market", Institute C.D. Howe Institute, Commentary No. 472, available at:

https://www.colhowe.org/sites/default/files/attachments/research_papers/mixed/ Update Commentary\%20472\%20web.pdf (4 June 2019).

16. Parham, A. G., Noland, T. G., Kelly, J. A. (2012), "Accounting Majors' Perceptions of Future Career Skills: An Exploratory Analysis", American Journal of Business Education, Vol. 5, No. 1, pp. 29-35.

17. PWC (2018), "Digitalisation in finance and accounting and what it means for financial statement audit", available at: https://www.pwc.de/de/im-fokus/digitaleabschlusspruefung/pwc-digitalisation-in-finance-2018.pdf (13 April 2019).

18. Smith, S. S. (2018), "Digitization and Financial Reporting - How Technology Innovation May Drive the Shift toward Continuous Accounting", Accounting and Finance Research, Vol. 7, No. 3, pp. 240-250.

19. Tekbas, I. (2018), "The Profession of the digital age: Accounting Engineering", available at:

https://www.ifac.org/global-knowledgegateway/technology/discussion/profession-digital-age-accounting-engineering (19 April 2019).

20. Wilson, R. A., Sangster, A. (1992), "The automation of accounting practice", Journal of Information Technology, Vol. 7, No. 2, pp. 65-75.

21. Zarowin, S. (1994), "CPA 2000: What's ahead for accounting software", Journal of Accountancy, Vol. 177, No. 3, pp. 54-58. 


\section{About the authors}

Danimir Gulin, Ph.D. is a Tenured Professor at the Department of Accounting, Faculty of Economics and Business, University of Zagreb. He received PhD in Accounting at the Faculty of Economics and Business Zagreb. He was also educated at the University of Graz, Austria, University of Kentucky, USA, and International Graduate School of Management - IESE, Barcelona, Spain. His main research interests are financial and managerial accounting, accounting for financial instruments and financial reporting. He is a member of Committee for Financial Reporting Standards (since 2007), and editor in chief of professional journal "Računovodstvo i financije" and "Riznica" (since 2007). He published numerous professional and scientific papers in international and national journals and participated in many scientific international conferences. The author can be contacted at dgulin@efzg.hr.

Mirjana Hladika, Ph.D. is an Assistant Professor at the Department of Accounting, Faculty of Economics and Business, University of Zagreb. She received PhD in Accounting at the Faculty of Economics and Business Zagreb. She was also educated at the Bodo Graduate School of Business, Norway, Center of Excellence in Finance, Ljubljana, Slovenia, and IFRS Foundation, London, United Kingdom. She participated in Erasmus Program at Hochschule fur Wirtschaft und Recht in Berlin, Germany. Her main research interests are financial and managerial accounting, accounting for financial instruments, financial reporting and integrated reporting, trends in accounting and accounting profession. She published numerous scientific papers in international and national journals and participated in many scientific international conferences. The author can be contacted at mhladika@efzg.hr.

Ivana Valenta is a Teaching and Research Assistant at the Department of Accounting, Faculty of Economics and Business, University of Zagreb. She received Master of Economics in Accounting at the Faculty of Economics and Business Zagreb. She attended Applied Time Series Econometric Methods and Forecasting Course in Zagreb. Her main research interests are financial and managerial accounting, accounting for financial instruments and integrated reporting. She published several professional and scientific papers and participated in several scientific international conferences. The author can be contacted at ivalenta@efzg.hr. 